\title{
Prenatal stress suppresses hunger-induced rat-pup killing in Long-Evans rats
}

\author{
WILLIAM M. MILEY \\ Richard Stockton State College, Pomona, New Jersey
}

\begin{abstract}
During each of the last 5 days of pregnancy, Long-Evans and Wister rats received $45 \mathrm{~min}$ of whole-body restraint and intense illumination. When they were 87 days old, they were placed on complete food deprivation until Day 90. At this time, all animals were tested with 1-day-old rat pups and adult mice (Mus musculus). The stress procedure suppressed the level of rat-pup killing induced by the food deprivation in the Long-Evans rats. The 3 days of food deprivation did not induce rat-pup killing in the other groups or mouse killing in any of the groups.
\end{abstract}

Many adult social and nonsocial behaviors are affected by events occurring during the perinatal period of development; these include such behaviors as sexual responses (Phoenix, Goy, Gerall, \& Young, 1959), rat-pup killing (Miley, Blustein, \& Kennedy, 1982; Rosenberg, Denenberg, Zarrow, \& Frank, 1971), open-field behavior (Denenberg, Karas, Rosenberg, \& Schell, 1968), and saccharine preference (Zucker, 1969). Regarding sexual responses, both male and female adult sexual behavior potentials are affected by the presence or absence of androgen during sensitive periods perinatally (Grady, Phoenix, \& Young, 1965). Genetic females exposed to perinatal androgen are defeminized and masculinized in reproductive physiology, morphology, and behavior (Pfeifer, Rotundo, Myers, \& Denenberg, 1976; Ward, 1969). Genetic males that have had perinatal androgen removed by castration are feminized and demasculinized (Grady et al., 1965; Ward, 1972). Masculinized neural mechanisms in mammals develop against a female trend only in the presence of fetal and neonatal testicular hormones during the last 7 days of gestation and the first 10 days after birth (Komisurak \& Diakow, 1973; Money \& Ehrhardt, 1971). When male rats are exposed to stress prenatally, they show feminized and demasculinized copulatory patterns in adulthood (Ward, 1972). In fact, prenatal stress suppresses the testosterone surge normally seen on Days 18 and 19 of gestation in male fetuses (Ward \& Weisz, 1980). In female rats, the issue is not so clear. Herrenkohl (1979) and Herrenkohl and Politch (1978) have reported that prenatally stressed females show alterations in cyclicity, pregnancy, and pup survival, whereas Beckhardt and Ward (1983), Meisel (1980), and Ward (1974) could find no such effects. Differences in methodology may account for the discrepancies.

The author's mailing address is: William M. Miley, Psychology Program, Richard Stockton State College, 1 College Drive, Pomona, New Jersey 08240.
Rat-pup killing by adult rats may also be subject to perinatal hormonal manipulations. Rosenberg et al. (1971) found that adult male Purdue-Wister rats kill and eat rat pups, but that females usually do not. Castration of the male blocks such killing, but long-term replacement therapy with testosterone propionate maintains a normal level of killing. Rosenberg and Sherman (1974) found that postnatal testosterone treatment was sufficient to induce killing ovariectomized female rats, but that prenatal testosterone was not necessary. Unfortunately, their experimental design did not allow for an independent evaluation of prenatal androgen.

Subsequently, Miley, Frank, and Hoxter (1981) showed that handling mothers of Long-Evans male rat offspring produced a high level of pup killing with or without the postnatal addition of exogenous testosterone. Using a modified (by us) prenatal stress procedure pioneered by Ward (1972), we (Miley et al., 1982; Miley et al., 1981) failed to find an independent prenatal stress effect on male and female offspring. These results may have occurred because of the extremely low rates of pup killing in our control groups.

This study was done to evaluate independently the possible effects of our prenatal stress procedure on ratpup killing. Because rats eat the pups they kill (Miley et al., 1982; Miley et al., 1981; Rosenberg et al., 1971), the rat-pup killing response could be motivated by predatory mechanisms. This study also attempted to evaluate how hunger might affect this response. The mouse-killing response by rats has also shown predatory components (e.g., Paul, Miley, \& Baenninger, 1971), so that it too was evaluated along with pup killing.

\section{METHOD}

Subjects

The subjects were male and female offspring of Wister and Long-Evans rats and were 91 and 92 days old at the time of behavioral testing. All animals were on ad-lib food and water 
Table 1

Rat-Pup Killing and Mouse Killing by Long-Evans and Wister Male and Female Rats Following Food Deprivation

\begin{tabular}{|c|c|c|c|c|c|c|c|c|}
\hline \multirow[b]{3}{*}{ Animals Killed } & \multicolumn{4}{|c|}{ Long-Evans } & \multicolumn{4}{|c|}{ Wister } \\
\hline & \multicolumn{2}{|c|}{ Male } & \multicolumn{2}{|c|}{ Female } & \multicolumn{2}{|c|}{ Male } & \multicolumn{2}{|c|}{ Female } \\
\hline & Fraction & $\%$ & Fraction & $\%$ & Fraction & $\%$ & Fraction & $\%$ \\
\hline & \multicolumn{8}{|c|}{ Prenatal Stress } \\
\hline Rat Pups & $6 / 18^{*}$ & 33 & $0 / 11^{*}$ & 0 & $1 / 10$ & 10 & $0 / 13$ & 0 \\
\hline \multirow[t]{2}{*}{ Mice } & $3 / 18$ & 17 & $2 / 11$ & 18 & $3 / 10$ & 30 & $1 / 13$ & 8 \\
\hline & \multicolumn{8}{|c|}{ No Stress } \\
\hline Rat Pups & $9 / 15^{*}$ & 60 & $7 / 18^{*}$ & 39 & $3 / 16$ & 19 & $2 / 15$ & 15 \\
\hline Mice & $0 / 15$ & 0 & $3 / 18$ & 17 & $3 / 16$ & 19 & $2 / 15$ & 13 \\
\hline
\end{tabular}

${ }^{*} p<.05$.

until 3 days prior to behavioral testing. At this time, they were deprived of food until the day of testing. The laboratory was maintained on a 12-h reverse light-dark cycle throughout the experiment.

\section{Procedure}

Female rats were mated in our laboratory and were assigned randomly to one of two experimental conditions: prenatal stress (S) or no manipulation (NS). During the last 5 days of gestation, Group $S$ received intense illumination from two $150-\mathrm{W}$ floodlights $(45.72 \mathrm{~cm}$ above the restraining apparatus) and were restrained in a Plexiglas rodent restraining device for 45 min each day. Group NS was not manipulated in any way during this time. On the 1st day after the day of birth, the neonates were cross-fostered to experimentally naive mothers that had just given birth. The newly cross-fostered litters remained intact until Day 23 following birth. At this time, all of the offspring were placed in standard laboratory cages in groups of two or three and remained untouched until 3 days prior to behavioral testing. At this time, all of the experimental animals were deprived of food until the time of testing. In addition, a group of animals that had not been prenatally stressed and were not deprived of food was formed. On the day prior to testing, all of the animals were separately placed in individual standard laboratory cages. The following groups were formed in a $2 \times 2 \times 2$ experimental design: male and female Wister and Long-Evans rats that either had or had not received prenatal stress. Following $24 \mathrm{~h}$ of social isolation, $2 \mathrm{~h}$ past the onset of the dark phase of the reverse light-dark cycle, each subject was tested for $.5 \mathrm{~h}$ with two neonatal rat pups and $.5 \mathrm{~h}$ with an adult mouse (Mus musculus) in a counterbalanced design.

\section{RESULTS}

Table 1 shows that 3 days of food deprivation produced higher rates of rat-pup killing in the nonstressed Long-Evans rats than in the stressed ones $\left(\chi^{2}=4.03\right.$, $\mathrm{p}<.05$ ). The level of hunger-induced rat-pup killing was apparently prevented by the prenatal stress manipulation. However, Fisher exact tests showed no differences between sexes in either the prenatally stressed group $(p>.05)$ or the nonstressed one $(p>.05)$. As seen in Table 1 , there were no differences in the Wister strain; the incidence of killing was low throughout.

Table 1 also shows that the experimental manipulations produced no differences in mouse killing; again, the incidence of killing was low throughout.

\section{DISCUSSION}

Prenatal stress seemed to suppress the level of hunger-induced rat-pup killing found in the Long-Evans animals. There did not seem to be any sex differences in the hunger-induced killing. The deprivation schedule used here had no effect on the Wister animals; thus, the presence or absence of a prenatal stress effect could not be evaluated. Wister animals are generally regarded as a more docile strain than the Long-Evans animals, which may account for the differences in the two strains. The mouse-killing measure was unaffected by the experimental manipulations.

That the rat-pup measure was affected by the food-deprivation schedule used here and the mouse-killing measure was not suggests that pup killing has more aspects in common with food getting (predation) than does mouse killing. However, this is not to say that cyclic food deprivation such as that used by Paul et al. (1971) would not lead to other results.

Prenatal stress seems to produce a desynchronization of elevation of testosterone titers in male fetuses and developing central nervous system structures (Ward \& Weisz, 1980), and may similarly affect in utero the masculinizing influences on female fetuses of androgen produced by the male fetuses through uterine circulation and/or amniotic diffusion (see Ward $\&$ Ward, in press). If rat-pup killing is to any extent androgen mediated, the suppression of pup killing in the stressed LongEvans animals may be accounted for by this desynchronization hypothesis.

\section{REFERENCES}

BeckhaRdT, S., \& WARD, I. L. Reproductive functioning in the prenatally stressed female rat. Developmental Psychobiology, 1983, 16, 111-118.

Denenberg, V. H., Karas, G. G., Rosenberg, K. M., \& Scheld, S. F. Programming life histories: An experimental design and initial results. Developmental Psychology, 1968, 1, 3-9.

Grady, K. L., Phoenix, C. H., \& Young, W. C. Role of the developing rat testis in differentiation of the neural tissues mediating mating behavior. Journal of Comparative and Physiological Psychology, 1965, 59, 176-182.

Herrenkohl, L. R. Prenatal stress reduces fertility and fecundity in female offspring. Science, 1979, 206, 1097-1099.

Herrenkoht, L. R., \& Politch, J. A. Effects of prenatal stress on the estrus cycle of female offspring as adults. Experentia, 1978, 34, 1240-1241.

Komisurak, B. R., \& Diakow, C. Lordosis reflex intensity in rats in relation to the estrus cycle, ovariectomy, estrogen administration and mating behavior. Endocrinology, 1973, 93, 548-557.

MEISEL, R. L. Effects of prenatal stress and uterine position on the sexual behavior and morphological differentiation of male 
and female rats. Unpublished master's thesis, Villanova University, 1980.

Miley, W. M., Blustein, J., \& Kennedy, K. Prenatal stimulation and postnatal testosterone affects infanticide in female rats. Physiology \& Behavior, 1982, 28, 627-629.

Miley, W. M., Frank, M., \& Hoxter, A. L. Rat-pup killing and maternal behavior in male Long-Evans rats: Prenatal stimulation and postnatal testosterone. Bulletin of the Psychonomic Society, 1981, 17, 119-122.

Money, J., \& Ehrhard, A. A. Fetal hormones and the brain: Effect on sexual dimorphism of behavior-A review. Archives of Sexual Behavior, 1971, 1, 241-263.

Paul, L., Miley, W. M., \& Baenninger, R. Mouse killing by rats: Roles of hunger and thirst in its initiation and maintenance. Journal of Comparative and Physiological Psychology, 1971, 76, 242-249.

Pfeiffer, W. D., Rotundo, R., Myers, M., \& Denenberg, V. Stimulation in infancy: Unique effects of handling. Physiology \& Behavior, 1976, 17, 781 .

Phoenix, C. H., Goy, R. W., Gerall, A. A., \& Young, W. C. Organizing action of prenatally administered testosterone propionate on the tissues mediating mating behavior in the female guinea pig. Endocrinology, 1959, 65, 369-382.

Rosenberg, K. M., Denenberg, V. H., Zarrow, M. X., \& Frank, B. L. Effects of neonatal castration and testosterone on the rat's pup-killing behavior. Physiology \& Behavior, 1971, 7, 363-368.

Rosenberg, K. M., \& Sherman, G. F. Testosterone induced pup-killing behavior in the ovariectomized female rat. Physiology \& Behavior, 1974, 13, 697-699.

WARD, I. L. Differential effect of pre- and postnatal androgen on the sexual behavior of intact and spayed female rats. Hormones and Behavior, 1969, 1, 25-36.

WARD, I. L. Female sexual behavior in male rats treated prenatally with an anti-androgen. Physiology \& Behavior, 1972, 8, 53-56.

WARD, I. L. Sexual behavior differentiation: Prenatal hormonal and environmental control. In R. C. Friedman, R. M. Richart, \& R. L. Vande Wiele (Eds.), Sex differences in behavior. New York: Wiley, 1974.

WARD, I. L., \& WARD, O. B. Sexual behavior differentiation: Effects of prenatal manipulations in rats. In N. Adler \& D. Pfaff (Eds.), Neurobiology of reproduction. New York: Plenum Press, in press.

WARD, I. L., \& WEIsz, J. Maternal stress alters plasma testosterone in fetal males. Science, 1980, 207, 328-329.

ZUCKER, J. Hormonal determinants of sex differences in saccharine preference, food intake, and body weight. Physiology \& Behavior, 1969, 4, 595-602.

(Manuscript received for publication July 15, 1983.)

\section{ERRATUM}

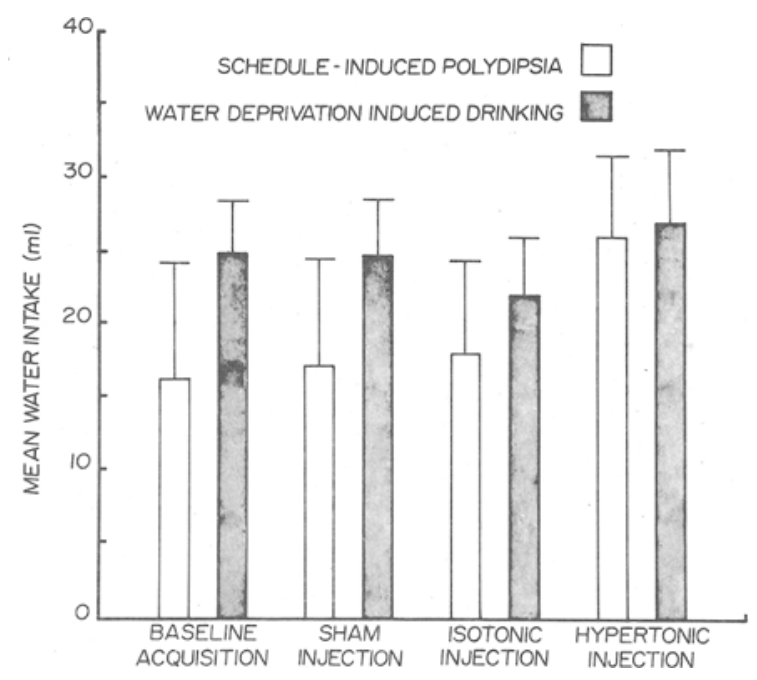

Figure 1. Mean water intakes for the schedule-induced polydipsia and water-deprivation-induced drinking groups are shown for each test condition. Plus one standard deviation is also shown.

McDonough, J. J., \& Porter, J. H. Schedule-induced and water-deprivation-induced drinking in rats: Effects of hypertonic saline challenges to homeostatic thirst mechanisms (Bulletin of the Psychonomic Society, 1983, 21, 403-406)-We ruefully acknowledge that, in the second column of page 405 , the wrong figure was published as Figure 1. The correct figure appears above. 